\title{
ESCOLA SEM PARTIDO - PRODUÇÃO DE SENTIDOS E DISPUTAS EM TORNO DO PAPEL DA ESCOLA PÚBLICA NO BRASIL'
}

\author{
SCHOOL WITHOUT PARTY - PRODUCTION OF SENSES AND DISPUTES AROUND THE \\ FUNCTION OF PUBLIC SCHOOL IN BRAZIL
}

\section{ESCUELA SIN PARTIDO - LA PRODUCCIÓN DE SENTIDOS Y CONTROVERSIAS SOBRE EL PAPEL DE LA ESCUELA PÚBLICA EN BRASIL}

\section{Elvis Patrik Katz \\ Andresa Silva da Costa Mutz ${ }^{2}$}

\section{RESUMO}

As disputas sociais acerca da educação vêm ocorrendo intensamente na contemporaneidade e colocam no centro da discussão a instituição escolar. A Medida Provisória (MP) do Ensino Médio, a Proposta de Emenda Constitucional (PEC) dos gastos públicos, as proposições do movimento Escola Sem Partido e as diversas ocupações estudantis nas escolas são manifestações muito claras da importância que nossa sociedade dá à educação. Nesse contexto, o presente artigo debate o papel da educação básica no Brasil, tendo em vista o seguinte paradoxo: como é possível que, em um cenário de tamanho descrédito para com o ensino público no qual proliferam enunciações que apontam para uma suposta "crise" da educação - existam tantas articulações e confrontos que objetivem o controle dessa instituição? Ou seja, como pode a escola pública brasileira ser, ao mesmo tempo, apresentada como culpada por inúmeros problemas e, estranhamente, aparecer como espaço em potencial onde todos os males da sociedade serão sanados? Assim, detemos nossa análise nas falas proferidas pelo Escola Sem Partido por meio de seu website oficial e em alguns artefatos da nossa cultura, com ajuda das contribuições do campo dos Estudos Culturais e do pensamento de Michel Foucault. Nossa hipótese é a de que esse movimento transite entre a crítica radical da escola e, ao disputar um espaço de exercício de poder, reafirme a potência da instituição nos dias de hoje.

PALAVRAS-CHAVE: Escola Sem Partido. Escola pública. Crise na educação. Discurso. Papel da escola.

\section{ABSTRACT}

The social disputes about education have been happening frequently in contemporaneity and they are putting academic institutions in the central point of discussions. The Medida Provisória (MP) of Ensino Médio, the Proposta de Emenda Constitucional (PEC) of public outgoings, the proposals of the Escola Sem Partido, and the many movements of occupations by students in schools are evident manifestations of the importance that our

\footnotetext{
${ }^{1}$ Mestrando em Educação - PPGEDU/FURG. Graduado em História Licenciatura - Universidade Federal do Rio Grande (FURG). Membro do Grupo de Estudos em Educação, Cultura, Ambiente e Filosofia (GEECAF/FURG) Rio Grande - RS, Brasil. Email: elviskatz@yahoo.com.br

${ }^{2}$ Licenciada em História, mestre e doutora em Educação. Membro do Núcleo de Estudos sobre Currículo, Cultura e Sociedade (NECCSO - UFRGS) e do Grupo de Estudos Educação, Cultura, Ambiente e Filosofia (GEECAF - FURG). Professora Adjunta do Instituto de Educação da Universidade Federal do Rio Grande (FURG) Rio Grande - RS, Brasil. Email: desacost@gmail.com
}

Submetido em: 30/11/2016 - Aceito em: 27/02/2017

(C) ETD-Educação Temática Digital Campinas, SP v.19 n.esp p. 184-205 jan./mar. 2017


society gives to education. In this context, the present article discusses the function of basic education in Brazil, planning the paradox: how is it possible that, in a scenery of great depreciation of public education - in which discourses point to the existence of a real "crisis" of education - there are many articulations and confrontations that aim the control of this institution? In other words, how can Brazilian public school be at the same time presented as guilty for innumerable problems and, strangely, appear as a potential space where all the evils of society will be solved? Therefore, we base our analysis on the speeches given by Escola Sem Partido, through its official website, and on some artifacts of our culture, with the help of contributions from the area of Cultural Studies and ideas of Michel Foucault. Our hypothesis is that this movement goes between the radical criticisms of school and, when fighting for a space of exercise of power, it reaffirms the potency of this institution nowadays.

KEYWORDS: Escola Sem Partido. Public school. Crisis in education. Speech. Role of the school.

RESUMEN

Conflictos sociales sobre la educación han ocurrido intensamente en la contemporaneidad y colocan en el centro de la discusión la institución escolar. La MP de la Escuela Secundaria, la nombrada PEC de los costos, las proposiciones del movimiento Escuela Sin Partido y las diferentes ocupaciones en las escuelas son manifestaciones muy claras de la importancia que nuestra sociedad atribuye a la escuela. En este contexto, el presente artículo debate acerca del papel de la escuela básica en Brasil tiendo en vista el siguiente paradojo: ¿cómo es posible que en un escenario de gran descrédito a la escuela pública - en el que los discursos argumentan a favor de la existencia de una verdadera "crisis" en la educación - haya tantas articulaciones y enfrentamientos que tienen como objetivo el control de esta institución? Es decir, ¿cómo puede la escuela pública brasileña presentarse al mismo tiempo como culpable por numerosos problemas y, curiosamente, también como un espacio en potencial, donde se resolverán todos los problemas sociales? De este modo, llevamos a cabo nuestros análisis de las declaraciones realizadas por la Escuela Sin Partido, a través de su página web oficial, y algunos artefactos de nuestra cultura, con la ayuda de las contribuciones del campo de los Estudios Culturales y el pensamiento de Michel Foucault. La hipótesis es que este movimiento se mueve entre la crítica radical de la escuela y, al disputar en este espacio del ejercicio del poder, reafirma la fuerza de la institución en la actualidad.

PALABRAS CLAVE: Escuela Sin Partido. Escuela pública. Crisis de la educación. Discurso. Papel de la escuela.

\section{INTRODUÇÃO}

Este texto tem por função trazer à tona o debate acerca do papel da escola pública no Brasil, levando em consideração as disputas discursivas contemporâneas sobre o tema. De modo geral, pretende-se verificar a possível existência de enunciações que ajudaram a conformar uma espécie de "cultura da crise" que afeta as formas pelas quais os professores e a própria instituição escolar são representados. Nesse contexto, cabem os questionamentos: como o movimento Escola Sem Partido se insere na discussão? Que tipo de contribuição ele dá para alimentar a culpabilização dos professores e da escola pelos supostos fracassos na educação que estaríamos presenciando? Veremos que, ao mesmo tempo em que estabelece uma crítica sobre os docentes e a escola, acaba-se por reforçar, também, a importância da existência de ambos, dado o imenso esforço empreendido para

(C) ETD-Educação Temática Digital Campinas, SP v.19 n.esp $\quad$ p. 184-205 jan./mar. 2017 
"descontaminar" esses espaços do que eles chamam de "doutrinação marxista". Não se trata, portanto, de um artigo com a finalidade de sugerir como a escola deve ser vista, mas de fazer a descrição das formas ambivalentes ${ }^{3}$ pelas quais a escola vem sendo colocada como objeto de disputa na cultura contemporânea.

O Escola Sem Partido foi fundado em 2004 por Miguel Nagib, mas foi precedido de toda uma tradição intelectual eminentemente liberal, conservadora e, segundo Miguel (2016), fundamentalista religiosa. Sua emergência remonta a chegada do Partido dos Trabalhadores ao Governo Federal por meio da vitória do candidato petista nas eleições de 2002, já que, segundo as teses do Escola Sem Partido, o mesmo seria o responsável por aparelhar o Estado (representado pela escola) ao processo de divulgação de ideologias específicas da esquerda. Sob o argumento de combater essa suposta "doutrinação ideológica" nos mais diversos sistemas de ensino brasileiros - com foco especial para a Educação Básica pública - o movimento tem um desenvolvimento singular que pode ser subdividido em três fases: um primeiro período reprodutivista, no qual os textos são copiados de outras fontes e de identidade ainda em construção; um segundo momento, em que o $\mathrm{ESP}^{4}$ começa a tornar-se notícia e passa a repercutir em alguns blogs ou sites sindicais, especialmente pelos imbróglios judiciais ${ }^{5}$ nos quais Nagib acaba envolvido devido sua atuação por meio do escolasempartido.org; a terceira fase inicia-se em 2014 quando, a partir da primeira tentativa da proposta de uma lei, o ESP fica bem mais conhecido e atuante, e o próprio Nagib passa a conceder diversas entrevistas em emissoras de televisão e rádio, além das falas destinadas à divulgação pela web. Ao contrário das simplificações presentes nas mídias jornalísticas, a trajetória do movimento nos mostra que suas enunciações se ligam diretamente aos jogos de poder e demais práticas não discursivas que vieram ocorrendo nos últimos 40 anos, aproximadamente. Portanto, o avanço das forças mais conservadoras, as crescentes expansões do pensamento neoliberal ou, até mesmo, a

\footnotetext{
3 Entendemos por ambivalência tanto as causas como os efeitos da função da linguagem em nomear e classificar as "coisas" do mundo, conforme delimitou Bauman (1999, p. 10). Essa característica tende sempre a produzir incertezas quanto ao sentido das proposições com relação à "realidade", já que ela parece estar sempre em mutação; da mesma forma, ao se empenhar cada vez mais para nomear e ordenar o "real", a Modernidade prolifera enormemente as ambiguidades.

"Em alguns casos optou-se pela sigla "ESP" no lugar de "Escola Sem Partido" com objetivo de tornar a leitura mais rápida e agradável.

${ }^{5} \mathrm{O}$ Caso COC tomou grandes repercussões na mídia nacional, tendo sido notícia na revista Veja, em meados de 2007. Basicamente, a rede de ensino COC processou o coordenador Miguel Nagib e a responsável por uma "denúncia" contra uma das apostilas utilizadas pela rede. Mais detalhes em: http://escolasempartido.org/caso-coc. Acesso em 04/11/2016.
}

(C) ETD-Educação Temática Digital Campinas, SP v.19 n.esp $\quad$ p. 184-205 jan./mar. 2017 
politização de grupos religiosos, tiveram papel decisivo ao lado do próprio sucesso acadêmico do marxismo (juntamente com as contínuas vitórias políticas do PT) na construção das condições de possibilidade para a irrupção do movimento. Em outras palavras, há uma série de imbricações entre saberes e poderes que estiveram envolvidas na produção de sujeitos (individuais e coletivos) contemporâneos. É possível perceber, por conta das nossas primeiras palavras, que partimos de dois campos de influência bem marcantes: os Estudos Culturais e o pensamento de Michel Foucault. No que se refere à influência dos EC, entendemos que "a cultura é teorizada como campo de luta entre os diferentes grupos sociais em torno da significação. A educação e o currículo são vistos como campos de conflito em torno de duas dimensões centrais da cultura: o conhecimento e a identidade" (SILVA, 2000, p. 32). Com o filósofo francês, adotamos uma analítica do poder que permite ver, nesses embates culturais, o lugar da produção de saberes "verdadeiros" como ferramentas de subjetivação dos sujeitos.

\footnotetext{
Temos antes que admitir que o poder produz saber (e não simplesmente favorecendo-o porque o serve ou aplicando-o porque é útil); que poder e saber estão diretamente implicados; que não há relação de poder sem constituição correlata de um campo de saber, nem saber que não suponha e não constitua ao mesmo tempo relações de poder (FOUCAULT, 2010, p. 30).
}

Dessa forma, seria muito simplificador submeter determinados fatos específicos a episódios marcantes de nossa história ${ }^{6}$ (a Ditadura Militar, por exemplo), como se fosse possível estabelecer relações causais entre processos históricos distintos. Assim, o que Foucault nos provoca a fazer é "uma tentativa permanente de deslegitimar o presente valendo-se da História, como um esforço para transformar o que se supõe natural em algo problemático e não forçosamente necessário" (SOUZA, 2011, p. 64). Na missão de desnaturalizar as obviedades, torna-se mais produtivo enxergar os ditos do movimento como táticas de luta na produção de sentidos da educação, em especial a respeito dos docentes, da escola e do currículo. Contudo, antes de chegarmos aos ditos do Escola Sem Partido, façamos a descrição de como a escola pública vem sendo analisada, discutida e julgada por seu valor nos últimos anos: esse é o objetivo da seção seguinte.

\footnotetext{
${ }^{6} \mathrm{Um}$ exemplo da tentativa de estabelecer um paralelo entre as práticas autoritárias do Regime Militar e as proposições do Escola Sem Partido está no texto de Moacyr Salles Ramos e Inez Stampa (2016).

(C) ETD-Educação Temática Digital Campinas, SP v.19 n.esp $\quad$ p. 184-205 jan./mar. 2017
} 


\title{
2 A ESCOLA PÚBLICA NO BRASIL, ENTRE A CRISE E A SALVAÇÃO
}

Com objetivo de tentar mostrar as formas pelas quais a escola é vista na sociedade contemporânea brasileira, convém a análise de algumas enunciações ${ }^{7}$ presentes na cultura que podem nos dar pistas disso. Podemos citar, por exemplo, a campanha do Ministério da Educação - MEC a respeito da $\operatorname{proposta}^{8}$ do Novo Ensino Médio. A narração possui, aproximadamente, um minuto de duração e está sendo apresentada intensivamente no rádio e na televisão brasileira. A propaganda patrocinada pelo Governo simula o ambiente de uma sala de aula na qual a professora é quem se dirige aos alunos para falar sobre a necessidade de reformas na educação. Ela usa exatamente estas palavras:

\begin{abstract}
Atenção, turma! Porque agora é hora de falar de educação. Vocês sabiam que a última avaliação da educação mostrou que o Brasil precisa melhorar muito o Ensino Médio? Isso mesmo. O desempenho dos jovens em matemática e português está menor do que há vinte anos. Duas décadas, gente! E hoje já são quase dois milhões de jovens que nem estudam, nem trabalham. Preocupante, né? A gente precisa virar essa página. Melhorar a educação dos jovens é uma das tarefas mais importantes e urgentes no Brasil. É pra ontem! (BRASIL, 2016).
\end{abstract}

Após esse trecho, a personagem da professora inicia a exposição do Novo Ensino Médio em si. Não é difícil notar que trinta e cinco segundos da propaganda são destinados, mais diretamente, para a crítica ao formato do Ensino Médio, à educação brasileira e, por consequência, à escola pública desse nível no Brasil. Quer dizer, mais da metade do tempo da peça midiática é gasta com a função clara de demonstrar a ineficiência e a incompetência do que está posto, o que não seria por si condenável, tendo em vista que o objetivo deve ser convencer os sujeitos de que o Novo Ensino Médio é necessário. De qualquer forma, podemos ver um aspecto muito interessante e que merece nossa atenção: vemos que, para questionar a qualidade do ensino existente, em sua fala, a personagem vale-se da estatística e da crítica aos fracassos na inserção dos estudantes no mercado de trabalho ou no Ensino

\footnotetext{
${ }^{7}$ A partir de uma perspectiva foucaultiana, podemos entender as enunciações como os elementos materiais e particulares pelos quais o enunciado se repete e aparece numa formação discursiva. Um discurso, portanto, é construído a partir de um conjunto de enunciados formados por enunciações específicas. Interessante notar que só podemos chamar de enunciação aquela fala que remete a um enunciado, o que subentende também que esse último faça parte de uma formação discursiva que lhe dá inteligibilidade e lhe impõe as regras e limites enquanto função enunciativa.

${ }^{8} \mathrm{Na}$ prática, por ter sido apresentada por meio de Medida Provisória (MP) e não ter perpassado nenhuma instância de discussão com a população em geral e os especialistas da área docente, em especial, tal reforma pode ser vista muito mais como uma imposição do que uma "proposição".
}

(C) ETD-Educação Temática Digital Campinas, SP v.19 n.esp $\quad$ p. 184-205 jan./mar. 2017 
Superior. Além disso, há, também, algumas expressões emblemáticas, como a que defende que é preciso "[...] virar essa página. Melhorar a educação dos jovens é uma das tarefas mais importantes e urgentes no Brasil. É pra ontem!" (BRASIL, 2016). Em conjunto, tanto a crítica ao modelo educativo atual, assim como o reforço de que é necessária uma reforma "urgente", convergem para um mesmo ponto; são enunciações que marcam as Políticas Públicas propostas pelo Estado (para justificar suas mudanças), a mídia e a própria literatura especializada que debate o papel da escola. Ou seja, são proliferações que acabam por naturalizar a ideia de que a educação - representada pela escola, o professor e o currículo tem importância na nossa sociedade, mas sempre precisa ser reformada, ajustada, melhorada, reinventada. A questão do currículo pode muito bem ser exemplificada por essa mesma MP do Ensino Médio, que pretende novamente modificar cargas horárias e hierarquizar disciplinas como mais ou menos importantes. Ainda poderíamos lembrar da discussão da BNCC que, além de levantar muita polêmica, se insere no mesmo contexto de sucessivas alterações que vêm sendo apresentadas como imperativos da educação brasileira.

Outro artefato muito interessante é uma reportagem publicada recentemente pelo site Zero Hora, do Rio Grande do Sul, na qual há uma série de ditos que merecem nossa atenção. Entretanto, o mais importante deles, talvez, seja o próprio título9: "Afinal, a escola privada é melhor do que a pública?". Em primeiro lugar, devemos pensar como uma pergunta dessas é formulada no interior de nossa cultura, isto é, como é possível que, em determinados momentos históricos, uma indagação tome como ponto de partida que as escolas privadas são melhores que as públicas para, em seguida, duvidar dessa proposição. O que estamos querendo dizer é que essa se constitui numa pergunta extremamente incomum na mídia, na literatura educacional e, mais ainda, nas práticas discursivas que têm origem nos representantes do Estado. Em realidade, apenas pelo título podemos supor, no mínimo, que o fracasso da escola pública é dado como um fato consumado, naturalizado. A manchete quer causar o estranhamento ao duvidar de uma tese que as avaliações governamentais e os exames de ingresso no Ensino Superior comprovam e, a partir de tal ponto, atrair o interesse do leitor. Todavia, a matéria não se limita ao título: todo o argumento - baseado em diversos dados quantitativos, depoimentos de especialistas e

\footnotetext{
${ }^{9}$ É importante perceber como os títulos das reportagens divulgadas pela mídia jornalística, em particular, constituem todo um material digno de investigação. Muito frequentemente, em tais manchetes, são evocadas estatísticas e afirmações mais ou menos polêmicas que, quase sempre, instauram o suposto estado de calamidade em que viveria a educação e a escola contemporâneas no Brasil.
}

(C) ETD-Educação Temática Digital Campinas, SP v.19 n.esp $\quad$ p. 184-205 jan./mar. 2017 
líderes sindicais e patronais - segue no sentido de convencer os leitores da seguinte tese: não é que a escola pública seja tão satisfatória quanto à privada, senão que a própria escola privada também merece críticas. Não se trata de afirmar uma falsa crise da escola pública ou questionar os seus métodos avaliativos, mas mostrar que, por meio de diversas táticas discursivas, a escola privada é tão ruim como a pública. Há, inclusive, a insinuação de que um dos motivos disso é que os professores (com formação deficitária) que atuam nas escolas são os mesmos, pois o baixo salário os faz buscar dupla jornada de trabalho (ZERO HORA, 2016).

Sintetizando, assim como na propaganda sobre o Novo Ensino Médio, novamente evoca-se a "crise da escola". Fiquemos com isso em mente, dois materiais distintos - um Estatal e outro da imprensa - reforçando, cada um ao seu modo, um estado de coisas acerca da escola. Claro que tudo isso não é por acaso, dado que os textos fazem parte da mesma sociedade e respondem aos mesmos regimes de verdade. A mídia, apontada muitas vezes como simples reprodutora de ideologias dominantes da burguesia, é também fabricada pela época em que está inserida. Segundo Rocha (2008, P. 127):

\begin{abstract}
Ao veicularem interessantes e interessados discursos, os meios de comunicação instituem e fazem circular verdades e representações, constituem nossas subjetividades e indicam as formas possíveis de como devemos ver e compreender o mundo em que vivemos. É principalmente através da mídia e do uso de variadas técnicas e tecnologias que se exercitam jogos de poder pelos quais estamos sendo sempre mais enredados e governamentalizados. Portanto, a mídia, ao veicular, organizar, definir, selecionar, construir uma determinada teia discursiva, utiliza-se de regras que acabam por, através de minuciosas e detalhadas operações, produzir algumas das verdades que, de algum modo, regulam nossos comportamentos e modos de agir e ser no mundo.
\end{abstract}

Vejamos agora se é possível enxergar enunciações desse mesmo tipo na literatura especializada no assunto. Em uma entrevista concedida no livro $A$ escola tem futuro?, o reconhecido pesquisador do campo da educação, José Carlos Libâneo, proferiu as seguintes palavras a respeito da situação da escola:

A escola continua sendo insubstituível; quem não usufruir dela não tem acesso às condições intelectuais e políticas de avaliação crítica da informação, de produção de conhecimento, de participação nos processos decisórios da sociedade. Temos que repensar essa escola, sim, precisamos ver o espaço escolar em relação a outros espaços, rever currículos, metodologias, formas de gestão (LIBÂNEO, 2007, p. 45).

(C) ETD-Educação Temática Digital Campinas, SP v.19 n.esp $\quad$ p. 184-205 jan./mar. 2017 
Esse breve trecho sintetiza em poucas palavras não apenas a ideia generalizada de que há, de fato, uma crise na educação e, principalmente, na escola brasileira. Mas sim, retoma um caráter visto também na propaganda que defendia a MP do Ensino Médio, sendo desse segundo aspecto que podemos tirar algumas conclusões ainda mais interessantes. Agora que podemos vislumbrar muito bem (pelo menos em três tipos de fontes diferentes) a dispersão do que vou chamar de discurso da crise, podemos começar a pensar de que maneira essas conclusões tornaram-se uma obviedade? Como foi que a ideia de uma crise da escola se generalizou tão fortemente a ponto de tornar-se uma verdade difícil de duvidar? Quais as práticas discursivas e as vontades de poder que fundamentam e dão lógica a concepção de que a escola não atende aos fins que deveria? Não se pretende responder a todas essas perguntas, mas usá-las como balizas para traçar um esboço provisório ao se pensar o tema.

Segundo Alfredo Veiga-Neto, conceber a existência de uma crise da escola só é possível a partir da aceitação de duas alternativas: a) se tomarmos a escola de forma idealizada, de modo que quaisquer outras formas existentes estariam "em crise" frente ao modelo essencializado; b) se aceitarmos que a sociedade vem se transformando rapidamente, assim como a cultura, e por suas características próprias a escola teria ficado atrasada em relação ao mundo contemporâneo (VEIGA-NETO, 2007, p. 103). Os dois caminhos só podem ser assim descritos visto que se orientam a partir de uma relação entre a escola e a cultura, entre a escola e a sociedade. Veiga-Neto explora muito mais a alternativa "b", ao mostrar que os tempos pós-modernos em que vivemos acabam sendo obstáculos ao modo de funcionamento da maquinaria escolar. "Em suma, não apenas a educação escolarizada está envolvida com a 'crise' da modernidade como, também e 'pior', ela é vista como ocupando uma posição central e desempenhando a função de causa da crise" (VEIGA-NETO, 2000b, p. 45). Com base nisso, ele desenvolve seu argumento no sentido de que a Modernidade e a Pós-Modernidade operam com ênfase nas estratégias de governamento $^{10}$ dos sujeitos, sendo elas distintas, mas não necessariamente opostas: a disciplina e o controle ${ }^{11}$.

\footnotetext{
${ }^{10}$ Como apontou Alfredo Veiga-Neto, o termo "governo" pode muito bem ser confundido, em nossa língua, com a noção de "Governo" enquanto representante do poder estatal. Então, ele propõe "[...] que o vocábulo governo - praticamente o único usado em textos foucaultianos, seja nas traduções para a língua portuguesa, seja nos textos escritos por autores de língua portuguesa - passe a ser substituído por governamento nos casos em que se estiver sendo tratada a questão da ação ou ato de governar (VEIGA-NETO, 2002, p. 19).

${ }^{11}$ A disciplina, para o caso que estamos nos referindo aqui, é "a forma do exercício do poder que tem por objeto os corpos e por objetivo sua normalização" (CASTRO, 2016, p. 110). O controle é marcado justamente pela expansão das disciplinas e implica "um tipo de poder que se exerce sobre os indivíduos sob a forma de vigilância individual e contínua [...] do castigo e da recompensa, e sob a forma da correção, ou seja, da formação e da transformação dos indivíduos em função de certas normas" (CASTRO, 2016, p. 85).
}

(C) ETD- Educação Temática Digital Campinas, SP v.19 n.esp $\quad$ p. 184-205 jan./mar. 2017 
O que tudo isso tem a ver com a escola? Muito... E a resposta não é difícil. Se a escola funcionou - e ainda funciona - como a grande fábrica de uma sociedade disciplinar, ou seja, uma instituição fabricando uma sociedade em que cada um deve ser capaz de exercer seu autogoverno, e se a sociedade pode prescindir cada vez mais desse autogoverno - na medida em que as novas tecnologias disseminam e barateiam a vigilância permanente -, então aquela primeira função que Kant ${ }^{12}$ tinha atribuído à educação escolar talvez esteja perdendo importância (VEIGANETO, 2007, p. 112).

Tal descrição é muito útil, pois nos permite refletir que o descompasso causado por essa suposta crise residiria no fato de estarmos caminhando num caminho diferente, enquanto sociedade, daquilo que os princípios iluministas da Modernidade nos prescreviam. O que explica em parte a existência das proposições que apresentamos há pouco; contudo, outros elementos podem ser colocados para melhor compreender esse processo. A alternativa "a", entretanto, nos parece tão ou mais interessante para responder à constituição dessa "crise" da escola. Nesse sentido, cabe refletir acerca da importância que os mais diferentes discursos desempenham sobre qual seria o "verdadeiro" papel da instituição. Vimos um exemplo disso na fala de Libâneo, quando esse autor definiu um dos problemas da escola e o motivo de sua reforma porque ela não atenderia a todas as atribuições humanistas que ele atribuiu, dentro da sua matriz teórica e ancorado por uma tradição crítica, ao estabelecimento de ensino em questão. Se estabelecermos o debate com o que acabamos de alegar, reafirmando a articulação entre os ideais iluministas e a escola, veremos que o próprio sentido do "fracasso" da escola se perde. Quer dizer, escola e Iluminismo estão imbricados de forma que um não pode ser causador da crise do outro, eles pertencem à mesma episteme. "Tais críticas só têm sentido se nos escorarmos no neoplatonismo e no ideologismo que comentei antes. Ora, é justamente tal escoramento, tal assunção a priori, que se deve evitar numa análise foucaultiana" (VEIGA-NETO, 2000a, p. 205). Justifica-se, assim, o motivo pelo qual escolhemos apresentar esse texto como uma descrição das formas pelas quais a escola vem sendo apresentada, em oposição ao caráter de prescrição existente na maioria dos textos sobre ela.

\footnotetext{
${ }^{12} \mathrm{O}$ autor está se referindo ao texto Sobre a pedagogia, de Kant, o qual reforça a ideia de que as crianças devem ir à escola, em primeiro lugar, para disciplinar seu tempo e seu espaço. Transmitir determinada carga de conhecimentos aos alunos seria originalmente, portanto, a função secundária da escola (VEIGA-NETO, 2007, p. 100).
}

(C) ETD-Educação Temática Digital Campinas, SP v.19 n.esp $\quad$ p. 184-205 jan./mar. 2017 


\begin{abstract}
Seja como for, o que me interessa mesmo é estudar a escola sem assumir, de antemão, que ela tem uma missão salvacionista ou que ela tem, por si mesma, o papel de formar moralmente os indivíduos. Em outras palavras, em vez de pensar que já sabemos o que é a escola. Prefiro examinar como ela se tornou o que é, como ela está envolvida com a sociedade em que se insere, como podemos entender melhor, através dela, as transformações que o está sofrendo (VEIGANETO, 2007, p. 98).
\end{abstract}

Temos uma ambivalência ainda maior quando se acha que a escola está em crise, tendo em vista que ela não atende aos projetos da pedagogia histórico-crítica ou freireana; por exemplo, mesmo que tais perspectivas devam muito aos ideais humanistas da modernidade, elas propõem certas conquistas sociais por meio dos bancos escolares que, na própria origem da instituição, não estavam presentes ou planejados. Quer dizer, no caso de observarmos a instituição escolar sempre pensando através de certas essências prédeterminadas e que não correspondem nem à sua história, nem às suas possibilidades, estaremos sempre em busca de "reformas" que encontrem, em algum ponto, a "verdadeira escola".

Há, então, uma série de "coisas ditas" em nossa sociedade que transitam no terreno ambíguo da crítica da escola e, inversamente, na tentativa de reformá-la e mantê-la em funcionamento. Desse ponto de vista, a escola existe na história, mas não corresponde ao que deveria promover, seja em termos de diminuição da desigualdade social ou em capacidade de formar cidadãos críticos. Ela teria inúmeras funções que permitiriam a formação integral dos estudantes, o que também acaba não acontecendo. Essa escola, ressaltamos, corresponde a certos tipos de discursos que - longe de olhar para a escola em função do que ela pode ou é dentro de seus limites - na prática querem mesmo é delimitar o futuro da instituição. São, portanto, vontades de poder sobre as instituições de ensino, as identidades docentes e os currículos. No entanto, poderíamos nos perguntar: por que dar tanta atenção a uma instituição quase obsoleta, como acabamos de descobrir? O que leva a escola a ser tão importante, ainda hoje? Mario Díaz pode nos oferecer o rastro dessa resposta:

\begin{abstract}
A pedagogia como prática discursiva propõe uma nova reflexão do discurso na sociedade dominada pelos discursos e pelos signos. Em tal sociedade, o discurso pedagógico transforma as estruturas fundamentais da subjetividade e das posições de sujeito. A análise da pedagogia deve especificar sua emergência, expansão e consolidação como dispositivo de intervenção e controle da vida social e individual dos sujeitos e como dispositivo de reprodução do poder (DíAZ, 1998, p. 23).
\end{abstract}

Portanto, mesmo que não estejamos mais na época da expansão do poder disciplinar, e que as escolas não tenham mais o papel fulcral que antes possuíam, ainda assim ela é uma instituição fundamental na disciplinarização dos corpos contemporâneos.

(C) ETD-Educação Temática Digital Campinas, SP v.19 n.esp $\quad$ p. 184-205 jan./mar. 2017 
Ao ensinar o autogoverno por meio da disciplina, as escolas formam consumidores com mais possibilidades de obter sucesso profissional, pois estabeleceriam certa resistência aos mecanismos de controle, para citar o exemplo mais claro do que vem se transformando a cidadania no modelo neoliberal de sociedade. Em síntese, a escola ainda se apresenta como uma instituição capaz de exercer determinadas formas de governar as crianças e os jovens de forma singular. A mídia, em geral, que também atua muito fortemente na subjetivação dos indivíduos com suas pedagogias culturais, é muito pouco delimitável e cambiante. A escola, por outro lado, pode ser regulada por meio de seu currículo, da formação e controle dos seus docentes e, por fim, pelas variadas possibilidades de reformas mais ou menos estruturais que pode sofrer. A partir de então, a escola, além do discurso pedagógico que ela oferta, constitui-se num instrumento pelo qual se luta no Brasil contemporâneo. Podemos comprovar essa tese a partir dos inúmeros confrontos sociais, políticos e culturais que vemos ocorrer atualmente: a) a polêmica acerca da Medida Provisória do Novo Ensino Médio: ao tentar reformar a estrutura e o currículo da escola de nível intermediário, afeta os próprios fins da educação escolar (educação para o trabalho ou para seguir nos estudos em nível superior, o preparo para a cidadania, etc); b) os movimentos de resistência ao corte de investimentos na educação, partindo da PEC dos gastos - como está sendo chamada - e evidenciando a importância que muitos grupos dão ao processo de educação oferecido pela escola pública; c) as múltiplas ocupações estudantis por estudantes secundaristas que vêm ocorrendo por todo território nacional, as suas bandeiras e demandas que reforçam o valor dado pelos próprios jovens à escola; d) os recentes embates acerca da aprovação dos Planos Municipais de Educação e dos Planos Estaduais de Educação, especialmente no que tange ao papel dos grupos religiosos interessados na não inclusão da nomeada "ideologia de gênero" nesses documentos; e) por fim, as proposições do movimento Escola Sem Partido, seja por meio das suas práticas discursivas ou das suas tentativas de aprovação de leis que controlem a prática docente, além da concorrência de várias perspectivas pedagógicas e das doutrinas políticas e ideológicas, com o foco de também fazer parte dos contextos escolares. Mostrar como o Escola Sem Partido entende essa escola de que tanto falamos, logo, é o objetivo da seção seguinte.

\section{O PAPEL DA ESCOLA NA ÓPTICA DO ESCOLA SEM PARTIDO}

Até aqui, fizemos um inventário um tanto apressado - mas suficiente - da forma que acreditamos ser predominante na cultura quando se refere ao papel da escola em nossa sociedade. Com tal descrição, esperamos ter mostrado que a instituição é vista sempre em estado de "crise", pois, no momento de analisá-la, por parte de quem faz a crítica, há,

(C) ETD-Educação Temática Digital Campinas, SP v.19 n.esp $\quad$ p. 184-205 jan./mar. 2017 
frequentemente, uma ideia pré-fixada de escola, o que gera o descompasso entre a ideia e a "realidade". Por outro lado, também é fato que muitos dos objetivos mais antigos da escola, em especial o seu funcionamento como uma maquinaria para disciplinar os sujeitos, veio perdendo importância em um mundo cada vez mais pautado pelo controle e autogoverno, ao invés da disciplina. Esses dois polos estão, provavelmente, entre as condições de possibilidade para o sentimento de que a escola fracassou. As manifestações do Governo, as mídias jornalísticas e a literatura especializada foram exemplos que escolhemos para tentar demonstrar como os sentidos de uma suposta "crise" proliferam e se atualizam em nossa cultura. Não é por acaso, portanto, que o discurso da crise é colocado em prática por todos aqueles que objetivam a reforma da escola ou da sociedade. Dito isso, tentemos descrever como o Escola Sem Partido se insere nessa discussão toda e de que maneira ele se aproveita das ambiguidades presentes no discurso da crise escolar.

O corpus de análise está composto por textos que foram retirados do site escolasempartigo.org. Eles se constituem das "abas" principais: "apresentação", "quem somos", "objetivos" e "FAQ". É importante ressaltar que, no projeto de dissertação que deu origem ao presente texto, há dois tipos de fontes ${ }^{13}$ no corpus documental, mas, neste artigo, analisamos apenas aquilo que denominamos como as falas de modelo, das quais fazem parte as "coisas ditas" apresentadas logo acima. Em todos esses escritos, o Escola Sem Partido coloca seus posicionamentos gerais acerca dos mais diversos temas relacionados com a educação. São nessas falas que o movimento se apresenta aos interessados e argumenta sobre suas demandas. Diferentemente dos artigos de opinião (que também fazem parte dessas falas de modelo, mas não são analisados aqui), nessas abas não são referenciados os seus autores, o que indica, certamente, que as enunciações presentes ali devem ser tomadas como bases para o ESP em sua totalidade; ou seja, elas não são apenas falas opinativas que o ESP concorda e assume como suas, mas têm ainda mais importância na medida em que é o movimento quem assume sua autoria.

Para analisar essas fontes, nos baseamos na chamada arqueologia de Michel Foucault, caracterizada por ser "uma espécie de teoria das práticas discursivas" (FISCHER, 2012, p. 24). É dela que extraímos a ideia de uma análise de discurso que, nas palavras de

\footnotetext{
${ }^{13}$ A outra categoria que nos referimos são as falas de controle, caracterizadas como aquelas que visam à normalização e a disciplinarização dos docentes, em geral com apelo ao procedimento jurídico, mas mesmo valendo-se de elementos advindos de outro campo do saber - o direito, e não a educação - estão atravessadas pela ordem discursiva que aponta para a crise da escola, a qual temos nos referido: são aquelas enunciações encontradas nos projetos de leis, nas notificações extrajudiciais, nas ameaças de processos por dano moral, etc.
}

C ETD-Educação Temática Digital Campinas, SP v.19 n.esp $\quad$ p. 184-205 jan./mar. 2017 
Foucault, não se confunde com a busca de uma origem, mas sintetiza uma forma geral de descrição que examina o já dito "no nível de sua existência; da função enunciativa que nele se exerce, da formação discursiva a que pertence [...]" (FOUCAULT, 2008, p. 149). Vemos, portanto, que a arqueologia não é uma hermenêutica, pois nela:

[...] é preciso ficar (ou tentar ficar) simplesmente no nível de existência das palavras, das coisas ditas. Isso significa que é preciso trabalhar arduamente com o próprio discurso, deixando-o aparecer na complexidade que lhe é peculiar. E a primeira tarefa para chegar a isso é tentar desprender-se de um longo e eficaz aprendizado que ainda nos faz olhar os discursos apenas como um conjunto de signos, como significantes que se referem a determinados conteúdos, carregando tal ou qual significado, quase sempre oculto, dissimulado, distorcido, intencionalmente deturpado, cheio de "reais" intenções, conteúdos e representações, escondidos nos e pelos textos, não imediatamente visíveis (FISCHER, 2001, p. 198).

Tal análise do discurso não busca, de modo algum, encontrar os verdadeiros sentidos de um texto, as influências de obras, livros ou autores. Consiste numa atitude que tenta mostrar as formas de funcionamento de formações discursivas, as maneiras pelas quais os discursos se colocam numa rede de poder contra outros discursos e, ainda, como estabelecem leis do que pode ou não ser dito em seu interior.

O problema dela [da arqueologia] é, pelo contrário, definir os discursos em sua especificidade; mostrar em que sentido o jogo das regras que utilizam é irredutível a qualquer outro; segui-los ao longo de suas arestas exteriores para melhor salientá-los. [É] uma análise diferencial das modalidades de discurso (FOUCAULT, 2008, p. 157-158).

Os discursos, em sua materialidade, podem ser estudados a partir dos seus enunciados, como já mencionamos brevemente antes. Cabe ressaltar que eles são justamente as "coisas ditas" e exercem o papel de uma função enunciativa que opera através de partículas da linguagem, como as frases, por exemplo, mas não se resumindo a elas. Os enunciados sempre dizem "algo", têm um papel específico e singular, limitado e repetível em uma lógica discursiva. O enunciado, portanto, só pode ser compreendido em sua relação com o discurso, já que esse é quem dá as chaves de verificação (a lógica de aceitação e entendimento) do próprio enunciado (FOUCAULT, 2008, p. 89-99). São os outros elementos enunciativos do discurso que qualificam um enunciado determinado enquanto tal, e é o conjunto dessas enunciações que fazem aparecer o discurso. Na descrição desses enunciados, deve-se atentar para o fato de percebê-los em sua superfície, no nível do que foi efetivamente dito. Mas isso não implica uma análise simplista ou ingênua; cumpre, pois,

C ETD-Educação Temática Digital Campinas, SP v.19 n.esp $\quad$ p. 184-205 jan./mar. 2017 
a tarefa de estudar as condições de possibilidade para a manifestação daqueles enunciados, e não outros. Ou seja, através da análise do discurso arqueológica, o objetivo reside na descrição das enunciações que aí estão, mas sempre com atenção especial para a história de como elas surgiram e como elas se configuraram como tal, a partir de quais regras, com quais contingências e determinações. Com isso em mente, temos que não basta olhar para corpus documental e encontrar obviedades, mas sim, ao tomar os acontecimentos discursivos em sua especificidade, notar como operam e que estratégias utilizaram para governar os sujeitos de seu tempo.

Colocadas as questões de método, passemos ao processo de análise dessas "coisas ditas" pelo Escola Sem Partido. Pensando nas tais "abas" mencionadas há pouco, podemos ver três pontos centrais que merecem destaque por constituírem uma série discursiva, isto é, serem repetidos de muitas formas, inúmeras vezes, nesse tipo de escritos que estamos nos detendo. E pela sua proliferação, acabam por naturalizar o objeto a que se referem. Em primeiro lugar, é possível identificar referências significativas acerca da "liberdade" no interior das instituições escolares. Segundo o movimento, a presença da doutrinação ideológica estaria causando certo constrangimento aos envolvidos no processo educativo; naturalmente, o aluno é visto como a maior vítima disso. Mais especificamente falando, a ausência de liberdade, ou sua diminuição, seria causada pela hegemonia das ideologias de esquerda no interior da escola. Antes de prosseguirmos, apenas uma questão para pensar: quando, desde sua concepção na Modernidade, a escola como instituição assumiu caráter neutro? A despeito do Regime ou Partido Político em vigor, pode a escola ensinar sem governar? Em outras palavras, é possível o exercício do saber sem relação com o poder? Prossigamos. O paralelo aos regimes totalitários é evidente: o Estado, ou os grupos que dele fazem uso, estariam tornando as escolas ferramentas da divulgação e propaganda dos ideais da esquerda ${ }^{14}$. Vejamos um exemplo dessa ideia:

\footnotetext{
${ }^{14}$ Naturalmente, essa "esquerda" evocada pelo Escola Sem Partido é uma generalização. Ela desconsidera as inúmeras polêmicas no interior das disciplinas e das próprias doutrinas políticas ligadas aos projetos que objetivam a mudança social e/ou o fim das desigualdades existentes. A retórica ocorre no sentido de dividir o "bem" do "mal", de modo que o adversário ideológico aparece sempre como um inimigo caricaturado, enquanto o próprio lado (nesse caso, a "direita") é visto como um campo muito complexo e no qual os autores recusam se enquadrar sob pena de suas bandeiras parecerem perspectivistas, ao invés de assumirem apenas as causas justas. Esse tipo de estratégia também pode ser visto muito frequentemente naqueles que se inserem na dita "esquerda".
}

(C) ETD-Educação Temática Digital Campinas, SP v.19 n.esp $\quad$ p. 184-205 jan./mar. 2017 
No Brasil, entretanto, a despeito da mais ampla liberdade, boa parte das escolas, tanto públicas, como particulares, lamentavelmente já não cumpre esse papel ${ }^{15}$. Vítimas do assédio de grupos e correntes políticas e ideológicas com pretensões claramente hegemônicas, essas escolas se transformaram em meras caixas de ressonância das doutrinas e das agendas desses grupos e dessas correntes (ESP, Apresentação, 2016, p. 01) ${ }^{16}$.

Hegemonia, portanto, que tolhe a liberdade dos estudantes. Referência também às próprias liberdades individuais, obviamente, tendo em vista o papel central dos liberais e neoliberais nas influências teóricas do ESP. Essa hegemonia certamente tem um caráter bem controverso, ainda mais levando em consideração a imensa dificuldade do Estado em instituir políticas públicas eficientes e/ou estruturais; as diversidades regionais, culturais, sociais e econômicas são gigantes de escola para escola. E há, ainda, o Projeto Político Pedagógico (PPP) que, enquanto documento de confecção coletiva, pode trazer ainda mais diferença para a identidade de uma escola. Se pensarmos ainda naqueles ideais pedagógicos mais ambiciosos, como o oriundo da obra de Paulo Freire, veremos que seus seguidores ainda enxergam a educação brasileira como "bancária". Quer dizer, falar em hegemonia de uma ou outra determinada corrente pedagógica ou política nas escolas parece um tanto problemático, daí a importância de fazê-la em termos pouco aprofundados, com muitas generalizações e apelo às vivências escolares daqueles sujeitos a serem governados - essas experiências atuam no sentido de fazer com que os indivíduos rememorem casos particulares em que teriam sido "doutrinados", para então tentar comprovar a tese do monopólio ideológico nas escolas.

Mas há mais: o movimento não se limita a detectar o problema da doutrinação nas escolas, senão que postula o modelo de escola que considera adequado. Segundo o ESP, "numa sociedade livre, as escolas deveriam funcionar como centros de produção e difusão do conhecimento, abertos às mais diversas perspectivas de investigação e capazes, por isso, de refletir, com neutralidade e equilíbrio, os infinitos matizes da realidade" (ESP, Apresentação, 2016, p. 01). Aqui, é possível enxergar mais uma estratégia muito comum nas proposições do movimento, e que demonstra, também, a sua heterogeneidade discursiva: trata-se da mistura entre afirmações bastante democráticas e algumas um tanto idealistas

\footnotetext{
${ }^{15}$ O "papel" citado pelo movimento é objeto de análise a seguir, quando descrevemos o modelo de escola proposto pelo Escola Sem Partido.

${ }^{16}$ Todas as referências aos ditos do Escola Sem Partido, aqui presentes, estão citadas da seguinte forma: em primeiro lugar, a expressão "ESP" para designar a autoria do texto pelo movimento; logo após, vem o título das "abas" mencionadas (apresentação, faq, objetivos, etc) e, por fim, o ano e a página dos documentos. Nesse sentido, as referências estão colocadas como no exemplo (ESP, Título da aba, ANO DO ACESSO, página).
}

(C) ETD-Educação Temática Digital Campinas, SP v.19 n.esp $\quad$ p. 184-205 jan./mar. 2017 
ou, às vezes, autoritárias. Como vimos anteriormente, o Escola Sem Partido quer se identificar como defensor da liberdade, mas, para isso, ele deve justificar a existência de algo que impeça o livre aprendizado dos alunos, para oposição. Não é à toa, portanto, que a proposição de uma escola democrática e livre seja sinalizada como a oposição ao modelo de escola que vemos hoje no Brasil. São duas ênfases que fazem parte do mesmo enunciado, poderíamos dizer, pois as duas atuam no sentido de fabricar certa percepção da escola como espaço de hegemonia ideológica e, por causa disso, a necessária intervenção nesse espaço para que se alcancem os ideais postulados. É impossível, no entanto, encerrar esse primeiro ponto sem considerar a palavra que citamos na última fala: "neutralidade". $\mathrm{Na}$ óptica do Escola Sem Partido, essa noção não tem o mesmo sentido que estamos acostumados, a neutralidade deve ser apenas a busca pela objetividade, o que implicaria na não aceitação de condutas explicitamente comprometidas politicamente. Aqui, entra uma controvérsia de grandes proporções, afinal, como se sabe, há toda uma tradição pedagógica "de esquerda" fundamentada sobre a crítica à ideia de neutralidade política e que defende abertamente a necessidade de posicionamento ideológico dos professores. Em geral, essa tradição assume que a própria tentativa de buscar a neutralidade significa assumir um lado político e, nesse sentido, é melhor ter consciência (sic) das suas práticas pedagógicas enquanto atos políticos do que simplesmente perseguir uma imparcialidade impraticável. Tal controvérsia oportunizaria outro artigo apenas para mostrar como cada paradigma se coloca ante a neutralidade. Para encerrar por aqui esse assunto, temos apenas que mencionar o fato da neutralidade, colocada pelo ESP, ser diferente daquela que encontramos tão criticada nas Ciências Humanas e na Educação; talvez pela trajetória de Nagib no direito, acreditamos que é desse pensamento jurídico e pretensiosamente objetivo que a neutralidade do movimento foi copiada. Sabe-se que, no campo das disputas judiciais, seja por força profissional, seja pela relação intrínseca que os discursos judiciais e a vontade de verdade mantêm desde os gregos, a objetividade e a neutralidade são de grande importância e aceitas quase sem muito questionamento.

Partindo para o segundo aspecto, ainda a respeito das fontes analisadas, também das "abas" do site: a centralidade dos professores na escola. Parece consenso, pelo menos entre os especialistas da educação, que vivemos um momento histórico da escolarização brasileira em que os gestores são supervalorizados da mesma forma que outrora os estudantes também foram. Quer dizer, já faz bastante tempo que o professor não é mais visto como a "autoridade em sala de aula", e os mais variados discursos pedagógicos vêm defendendo cada vez mais a função docente enquanto facilitadora, como se assumisse a função de um auxiliar que dialoga com estudantes e constrói, com eles, o conhecimento. Todo esse debate atual fica de lado, talvez até por ignorância de seus defensores que não

C ETD-Educação Temática Digital Campinas, SP v.19 n.esp $\quad$ p. 184-205 jan./mar. 2017 
provêm do campo da educação, nos ditos do Escola Sem Partido. Para o grupo, os professores são figuras de poderes plenos e absolutos, capazes de "fazer a cabeça" dos estudantes como quiserem. Os docentes seriam militantes de esquerda que, por iniciativa de algum projeto maquiavélico, estariam doutrinando crianças e jovens largamente; a prova seria que "segundo pesquisa realizada pelo instituto sensus [...], a imensa maioria dos professores (78\%) acredita que a principal missão da escola é 'despertar a consciência crítica dos alunos'”' (ESP, Faq, 2016, p. 01).

Em tal ponto, temos que esclarecer, também, o que significa essa "crítica" mencionada pelo movimento e que seria supostamente "transmitida" pelos professores aos alunos. Para o ESP, o problema reside no fato de que a crítica feita pelos professores "doutrinadores" seria sempre direcionada aos alvos da direita política, como o capitalismo, a burguesia, a igreja católica, a família, a propriedade privada, os Estados Unidos da América, entre outros. $O$ argumento do movimento é o de que deveria haver, também, a crítica aos projetos sociopolíticos da própria esquerda, como "a repressão política e o fracasso econômico da antiga União Soviética" ou "os campos de reeducação e trabalho forçado na China comunista" (ESP, Faq, 2016, p. 01). Enfim, os docentes descritos pelo ESP seriam, no mínimo, críticos parciais e, quando fosse necessário, até mentiriam para justificar eventuais erros da "esquerda" e crucificar qualquer elemento da "direita". E o que o Escola Sem Partido propõe para resolver esse problema? Segundo eles, "é fundamental que as escolas adotem medidas concretas para assegurar a diversidade de perspectivas ideológicas nos seus respectivos corpos docentes. Afinal, em matéria de conhecimento, o pior dos mundos é o do monopólio ideológico" (ESP, Objetivo, 2016, p. 01). Ao evocar mais uma vez o argumento de uma suposta hegemonia da "esquerda", o movimento advoga para que as escolas garantam a diversidade de perspectivas ideológicas nas escolas, com a contratação de um corpo docente plural. Novamente, mais uma situação que se assemelha a um paradoxo: em primeiro lugar, não é difícil encontrar nas "coisas ditas" pelo grupo uma tentativa de normalização das identidades docentes. Esse é, inclusive, o cerne dos projetos de leis em andamento. Contudo, nesse trecho, defende-se que existam posturas diferentes na escola com o objetivo de garantir as liberdades de aprendizado dos alunos. Em nível hipotético, poderíamos dizer que, de fato, o ESP defende o pluralismo, mesmo que isso possa muitas vezes significar apenas uma tática de governamento dos sujeitos, mas essa diversidade ocorre de maneira controlada: dessa maneira, os professores e as escolas teriam a liberdade de postular a diversidade, mas os limites disso estariam nas leis contra a doutrinação e, fundamentalmente, nos princípios estabelecidos pelas famílias dos alunos. Nada mais ambivalente: para ser plural, a escola - por força da lei - precisa cercear com

C ETD-Educação Temática Digital Campinas, SP v.19 n.esp $\quad$ p. 184-205 jan./mar. 2017 
limites claros o trabalho do professor, prescrevendo-lhe modos de ser sujeito de forma a atender determinadas expectativas do que se supõe ser um "bom professor"; leia-se "um bom professor para o regime capitalista avançado", como conhecemos na contemporaneidade.

Por último, então, o terceiro foco do Escola Sem Partido, ao descrever a escola contemporânea: a relação entre a instituição escolar e a instituição familiar. Basicamente, para o movimento, alguns temas são morais e vão de encontro com as convicções dos pais. Haveria, a partir de então, barreiras que a escola e o professor não poderiam transgredir, pois estão pautadas pela família ou pela própria religião do estudante. A respeito disso:

\begin{abstract}
As conexões entre moral e religião, e a manifesta impossibilidade de que se possa ter uma moral republicana, constituem uma questão forte da argumentação [...] Religião e família parecem constituir as únicas fontes para o estabelecimento de princípios morais, e vale dizer que postas assim, no singular, ou seja, uma dada religião, que fica sempre suposta como a católica, e uma dada família, sempre suposta a família monogâmica heterossexual (SEFFNER, 2016, p. 10).
\end{abstract}

Segundo Seffner, logo, haveria no pensamento do ESP uma forte valorização das instituições familiares e religiosas, bem como um consequente decréscimo da função do Estado na educação dos jovens. Miguel (2016, p. 616) segue na mesma linha ao afirmar que as proposições do grupo ignoram o caráter republicano da escola e afirmam a soberania da família no processo educativo das crianças e adolescentes. Ao analisar o artigo IV de um dos projetos de leis baseados na minuta disponibilizada pelo Escola Sem Partido, Seffner afirma que:

[...] ele atrela a educação escolar aos valores morais das famílias, não atentando para o fato de que o ingresso da criança na escola pública é seu ingresso em um ambiente de circulação de diversos códigos morais, aos quais se deve conhecer, e aprender a respeitar desde que não violem a legislação vigente. A ideia de que a educação escolar é uma continuação da educação familiar, e de que a professora é uma segunda mãe, estão manifestas nesse modo de compreender as coisas (SEFFNER, 2016, p. 09).

Essa soberania da educação familiar sobre a educação fornecida pelo Estado coloca a escola pública novamente em uma situação ambivalente. Agora, ao invés de inserir as crianças e jovens num espaço de contato com a diferença, a escola ressurge nos documentos do ESP como simples transmissora de conteúdos e, portanto, sem nenhuma função de socialização ou de construção intencional da cidadania. Tais propostas colocam

(C) ETD-Educação Temática Digital Campinas, SP v.19 n.esp $\quad$ p. 184-205 jan./mar. 2017 
em xeque grande parte das teorizações do campo pedagógico nos últimos anos, assim como as muitas passagens presentes nas legislações que sucederam após a Lei de Diretrizes e Bases da Educação Nacional (LDB) de 1996. Numa espécie de liberalismo educacional, o ESP parece indicar que a construção da cidadania e da liberdade dos estudantes deve se dar em outro plano e sem a ação direta do Estado, de modo que competiria à escola pública tão somente exercer o papel de informar, em busca da objetividade e da neutralidade.

A título de síntese, vimos que o ponto de vista do movimento é que a escola é extremamente importante, em especial por ser a instituição capaz de transmitir os conteúdos da cultura ocidental aos estudantes. A "descontaminação e desmonopolização política e ideológica das escolas" (ESP, Objetivos, 2016, p. 01) seria a condição essencial para que ela alcance seu papel de mudar a sociedade para "melhor". O paralelo com o neoliberalismo é evidente: o Estado deve interferir o mínimo possível para o progresso; da mesma forma, a escola deve apenas transmitir os conteúdos, sem qualquer compromisso político específico ou agenda social pré-determinada. Os docentes, da mesma forma, devem ser bem distribuídos quanto a suas concepções ideológicas, mas devem obedecer à certa normalidade que não ultrapasse as convicções familiares dos estudantes. Sob o ponto de vista da "crise" da escola de hoje, o ESP acaba reforçando a importância da instituição na medida em que luta tão intensamente por ela; uma evidência, portanto, do caráter ambivalente que marca a escola contemporânea. O que se supõe é, assim, tratar-se de um tema complexo e não passível de simplificações comuns a pensadores como os fundadores do ESP, jornalistas que produzem conteúdos para os canais midiáticos, ou mesmo os profissionais da área jurídica - oriundos de um campo exterior e não preparados para lidar com tal complexidade - ao contrário daqueles que provêm da educação, filosofia, sociologia, história e/ou pedagogia. O movimento também acaba por valorizar a função do professor, pois atribui a ele a tarefa de conduzir como sujeito único todo o processo educativo. É claro que isso não acontece por benevolência do ESP; ao contrário, fora de uma concepção de professor sustentada pela autoridade e pela busca da neutralidade não há lugar para esse profissional. Assim, ao criticar as práticas supostamente ideológicas, desqualifica-se o trabalho de inúmeras escolas de todo Brasil, fazendo com que seus esforços contra as imensas dificuldades estruturais apareçam aos olhos das famílias como simples propaganda ideológico-partidária.

(C) ETD-Educação Temática Digital Campinas, SP v.19 n.esp $\quad$ p. 184-205 jan./mar. 2017 


\section{CONCLUSÃO}

Ao longo deste trabalho, nós tentamos pensar a aparente controvérsia existente nas "coisas ditas" do Escola Sem Partido e, mais amplamente, nos inúmeros discursos que emanam ou circundam a educação escolar. Esse discurso propagava uma "cultura da crise", ao definir a escola como uma essência que não corresponderia aos objetivos propostos originalmente na época do lluminismo, ou por não contemplar as muitas atribuições que lhe foram outorgadas ao longo do tempo, como promover uma educação "crítica", por exemplo. Observamos que o ESP e outros tipos de ditos que proliferam na contemporaneidade executam uma função de comentário a esse discurso da crise, dado que o repetem largamente por meio de inúmeras enunciações, mas o fazem sempre de maneira singular e situada historicamente. Esperamos ter apresentado um panorama geral de como a produção de sentidos e as disputas em torno do papel da escola pública vêm ocorrendo para que nós - enquanto educadores e pesquisadores - possamos resistir aos discursos que nos atravessam em tempos tão sombrios.

\section{REFERÊNCIAS}

AFINAL, a escola privada é melhor do que a pública? Zero Hora, Porto Alegre, 11 de nov. de 2016. Disponível em: < http://zh.clicrbs.com.br/rs/vida-eestilo/educacao/noticia/2016/11/afinal-a-escola-privada-e-melhor-do-que-a-publica8240055.html>. Acesso em: 26.11.2016.

BAUMAN, Zygmunt. Modernidade e ambivalência. Rio de Janeiro: Jorge Zahar, 1999.

BRASIL. Ministério da Educação. Comerciais entram no ar hoje, 28, e focam no protagonismo do estudante. Disponível em: <https://youtu.be/QA3F9k-pgYk>. Acesso em: 26.11.2016.

CASTRO, Edgardo. Vocabulário de Foucault. 2 ed. Belo Horizonte: Autêntica, 2016.

DÍAZ, Mario. Foucault, docentes e discursos pedagógicos. In: SILVA, Tomaz Tadeu da (Org.). Liberdades reguladas: a pedagogia construtivista e outras formas de governo do eu. Petrópolis: Vozes, p. 14-29, 1998.

(C) ETD-Educação Temática Digital Campinas, SP v.19 n.esp $\quad$ p. 184-205 jan./mar. 2017 
ESCOLA SEM PARTIDO. Apresentação. 2016. Disponível em:

<http://escolasempartido.org/apresentacao>. Acesso em: 26.08.2016.

26.07.2016.

FAQ. 2016. Disponível em: http://www.escolasempartido.org/faq. Acesso em:

Quem somos. 2016. Disponível em: <http://escolasempartido.org/quem-somos>.

Acesso em: 26.08.2016.

Objetivos. 2016. Disponível em: http://www.escolasempartido.org/objetivos.

Acesso em: 26.07.2016.

FISCHER, Rosa Maria Bueno. Foucault e a análise do discurso em educação. Cadernos de Pesquisa. Rio de Janeiro, n. 114, p.197-223, 2001.

editora, 2012.

Trabalhar com Foucault: arqueologia de uma paixão. Belo Horizonte: Autêntica

FOUCAULT, Michel. A Arqueologia do Saber. Tradução: Luiz Felipe Baeta Neves, 7 ed. Rio de Janeiro: Forense Universitária, 2008.

. Vigiar e punir: nascimento da prisão. Tradução de Raquel Ramalhete. 38 ed.

Petrópolis: Vozes, 2010.

LIBÂNEO, José Carlos. A escola com que sonhamos é aquela que assegura a todos a formação cultural e científica para a vida pessoal, profissional e cidadã. In: COSTA, Marisa Vorraber (Org.). A escola tem futuro, 2 ed. p. 23-52, 2007.

MIGUEL, Luis Felipe. Da "doutrinação marxista” à" ideologia de gênero"-Escola Sem Partido e as leis da mordaça no parlamento brasileiro/From "Marxist indoctrination" to "gender ideology": Escola Sem Partido (non-partisan school) and gag laws in Brazilian congress. Revista Direito e Práxis, v. 7, n. 15, p. 590-621, 2016.

RAMOS, Moacyr Salles; STAMPA, Inez. SUBVERSÃO E RESISTÊNCIA DOCENTE: Notas sobre a ditadura militar e o movimento Escola sem Partido. Revista Espaço do Currículo, v. 9, n. 2, 2016.

ROCHA, Cristianne Maria Farmer. A escola na mídia: entre inovações e controles. Educação Temática Digital, v. 9, p. 126, 2008.

SEFFNER, Fernando. Atravessamentos de gênero, sexualidade e educação: tempos difíceis e novas arenas políticas. In: Reunião Científica Regional da ANPED. Curitiba: ANPED, 2016.

(C) ETD-Educação Temática Digital Campinas, SP v.19 n.esp $\quad$ p. 184-205 jan./mar. 2017 
SILVA, Tomaz Tadeu da. Teoria Cultural e Educação: Um vocabulário Crítico. Belo Horizonte: Autêntica, 2000.

SOUZA, Washington Luis. Michel Foucault e o uso filosófico da História. Páginas de Filosofia, v. 3, n. 1-2, p. 49-66, 2011. Disponível em:

<http://www.bibliotekevirtual.org/revistas/Metodista-SP/PF/v03n1-2/v03n1-2a02.pdf>. Acesso em 23.08.2016.

VEIGA-NETO, Alfredo. Educação e governamentalidade neoliberal: novos dispositivos, novas subjetividades. In: PORTOCARRERO, Vera; CASTELO BRANCO, Guilherme. Retratos de Foucault. Rio de Janeiro: Nau Editora, p. 179-217, 2000a.

Michel Foucault e os Estudos Culturais. In: COSTA, Marisa Vorraber (Org.). Estudos Culturais em educação: Mídia, arquitetura, brinquedo, literatura, cinema... Porto Alegre: Editora da UFRGS, p. 37-72, 2000b.

. Coisas do governo. In: RAGO, Margareth; ORLANDI, Luiz BL; VEIGA-NETO, Alfredo. Imagens de Foucault e Deleuze: ressonâncias nietzschianas. Rio de Janeiro: DP\&A, p. 13-34, 2002.

Pensar a escola como uma instituição que pelo menos garanta a manutenção das conquistas fundamentais da Modernidade. In: COSTA, Marisa Vorraber (Org.). A escola tem futuro, 2 ed. p. 97-118, 2007.

\footnotetext{
' Revisão gramatical do texto por: Eugênia Adamy Basso
} 